\title{
Primary Cutaneous Diffuse Large B-Cell Lymphoma Involving the Peripheral Blood and Prostate: A Case Report
}

\author{
Dr. Manim Amatya ${ }^{1 *}$, Dr. Anil Dev Pant ${ }^{1}$, Dr. Gita Sayami ${ }^{1}$, Dr. Shova Banstola ${ }^{1}$
}

${ }^{1}$ Pathologist, Grande International Hospital, Dhapasi, Kathmandu, Nepal

DOI: $10.36348 /$ sipm.2021.v06i02.007

| Received: 03.02.2021 | Accepted: 17.02.2021 | Published: 24.02.2021

*Corresponding author: Dr. Manim Amatya

\section{Abstract}

The skin, genital system, and hematological involvement of diffuse large B-cell lymphomas are quite rare. Diagnosis and disease classification are based on histological review and immunohistochemical staining. PCDLBCL is an aggressive lymphoma with an inferior prognosis. However, timely recognition can have important clinical and therapeutic implications.

Keywords: Diffuse Large B-cell lymphoma, Skin, Prostate, Blood.

Copyright () 2021 The Author(s): This is an open-access article distributed under the terms of the Creative Commons Attribution 4.0 International License (CC BY-NC 4.0) which permits unrestricted use, distribution, and reproduction in any medium for non-commercial use provided the original author and source are credited.

\section{INTRODUCTION}

Primary cutaneous B cell lymphoma is a rare and fast-growing neoplasm that accounts for 25 to $30 \%$ of all cutaneous lymphomas [1]. They are classified into three distinct subgroups by 2008 World Health Organization-European Organization for Research and Treatment of Cancer (WHO-EORTC) joint classification: primary cutaneous follicle center lymphoma (PCFCL), primary cutaneous marginal zone lymphoma (PCMZL), and primary cutaneous diffuse large B-cell lymphoma (PCDLBCL) [2]. Pathologic review and an appropriate staging are necessary to distinguish primary cutaneous B-cell lymphomas from systemic B-cell lymphomas with secondary skin involvement [3]. PCFCL and PCMZL are indolent lymphomas that rarely disseminate to extracutaneous sites and have a better prognosis, whereas PCDLBCL is an aggressive lymphoma with an inferior prognosis [4]. We report the case of a man who developed primary cutaneous diffuse large B-cell lymphoma (PCDLBCL) with involvement of the prostate and peripheral blood.

\section{CASE REPORT}

A 79 year old male patient presented to dermatology OPD with history of multiple indurated non-mobile pruritic plaques over abdomen, left axilla and cheek since one and half months. The patient also complained of decreased urinary flow, nocturia, incomplete voiding and straining. There was associated weight loss and loss of appetite. However, there was no history of fever, night sweats. The patient also had taken a full course of Anti-tubercular therapy 26 years back for Tuberculosis.

On clinical examination there was no lymphadenopathy or hepatosplenomegaly. On digital rectal examination, the prostate was found to be enlarged, firm to hard, and nodular.

Ultrasonography confirmed moderate enlargement of the prostate with bilateral hydronephrosis (Right $>$ Left). Biochemical tests showed significantly raised Lactic Acid Dehydrogenase (601 U/L). Serum Prostate Specific Antigen total was 0.79 $\mathrm{ng} / \mathrm{ml}$. Peripheral blood smear showed $18 \%$, atypical cells. These cells showed increased nucleo-cytoplasmic ratio with round to oval irregular nuclei, occasionally 1 3 prominent nucleoli, irregularly clumped chromatin and scant amount of agranular cytoplasm.

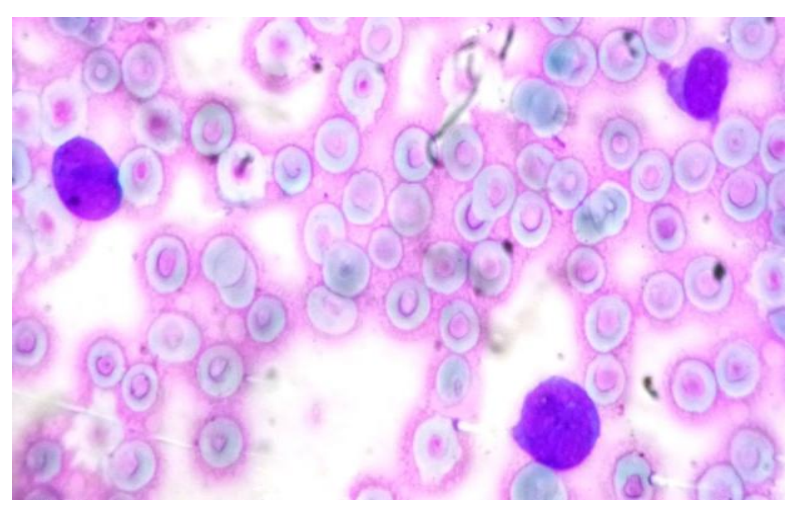

Fig-1A: Peripheral blood smear - Shows atypical lymphoid cells, Giemsa stain $20 \mathrm{X}$ 


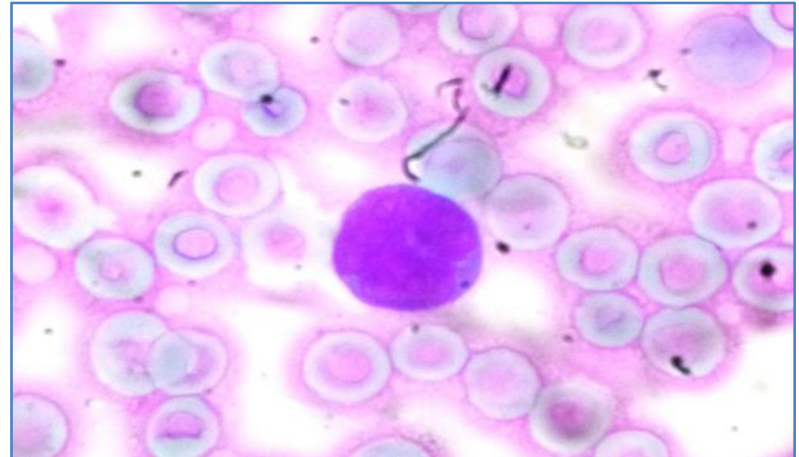

Fig-1B: Peripheral blood smear showing atypical lymphoid cells, Giemsa stain $40 \mathrm{X}$
Skin punch biopsy of $4 \mathrm{~mm}$ was taken from an abdominal skin lesion. The specimen was sent for histopathology. Microscopic examination showed unremarkable epidermis with underlying dermis showing fibrocollagenous stroma and adenexa. The mid-dermis to subcutis showed diffuse proliferation of small to intermediate sized lymphoid cells, with mild atypia along with crushed cells (?lymphoid). Typical epidermotropism was not seen. A diagnosis of cutaneous lymphoid infiltrate was made. Customized immunohistochemistry (including lymphoma markers) was advised to rule out possibility of Non-Hodgkin lymphoma.

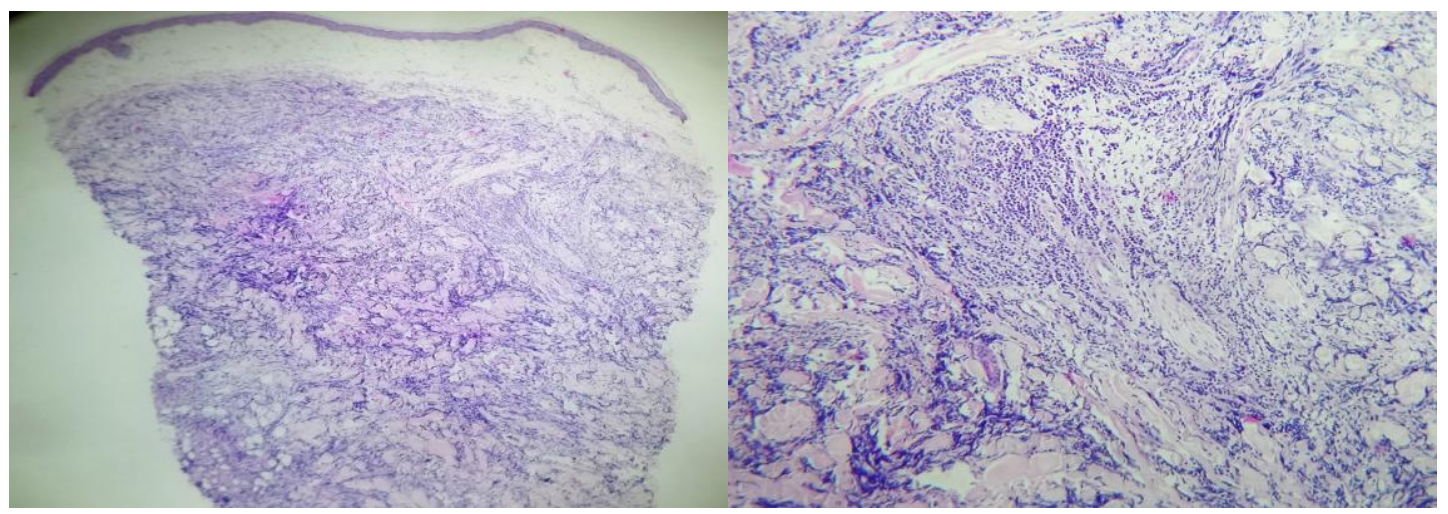

Fig-2A and 2B: Skin biopsy showing diffuse dermal infiltrate of atypical lymphoid cells. $\mathrm{H}$ and $\mathrm{E}, \mathrm{4X}$ and 10X hematoxylin and eosin

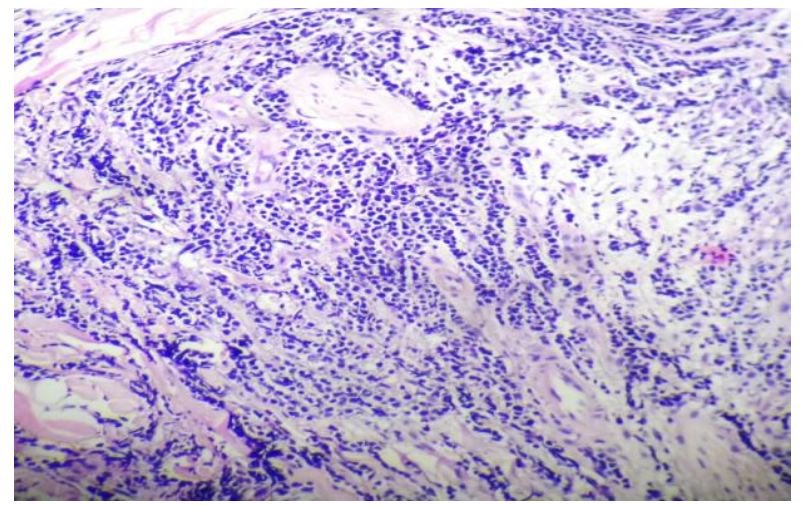

Fig-2C: Skin biopsy showing dermal infiltrate of atypical lymphoid cells $H$ and $E, 20 X$

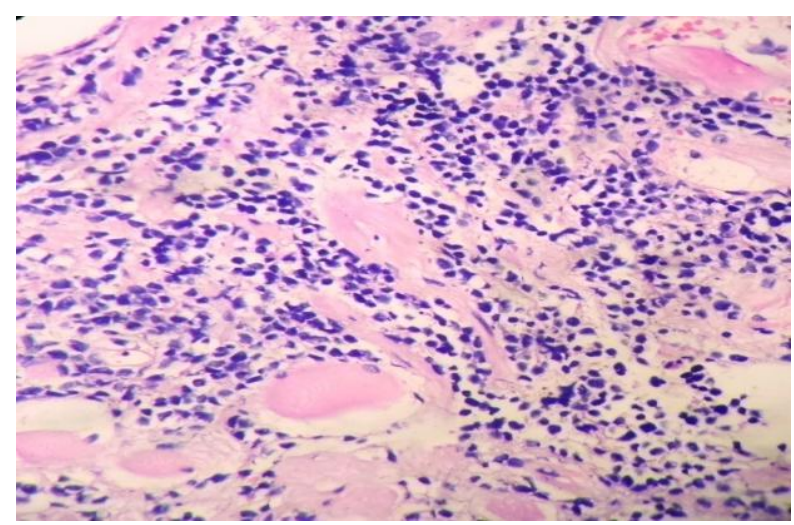

Fig-2D: Skin biopsy showing dermal infiltrate of atypical lymphoid cells. $H$ and $E, 40 X$
Immunohistochemistry (IHC) of skin biopsy expressed positivity for the markers CD3, CD20, PAX5, CD10, CD43, and BCL-2. Ki-67 was immunoreactive in $70 \%$ tumor cells which was compatible with PCDLBCL.

Bipolar TURP (transurethral resection of the prostate) was done for Benign Enlargement of Prostate. Histopathology showed prostatic tissue with small foci showing infiltration of intermediate sized atypical lymphoid cells within the prostatic stroma with similar morphology as seen on skin biopsy. Final Impression was benign prostatic hyperplasia with focal infiltration by lymphoma cells. It was advised for IHC for definite typing and to correlate with skin biopsy findings including IHC.

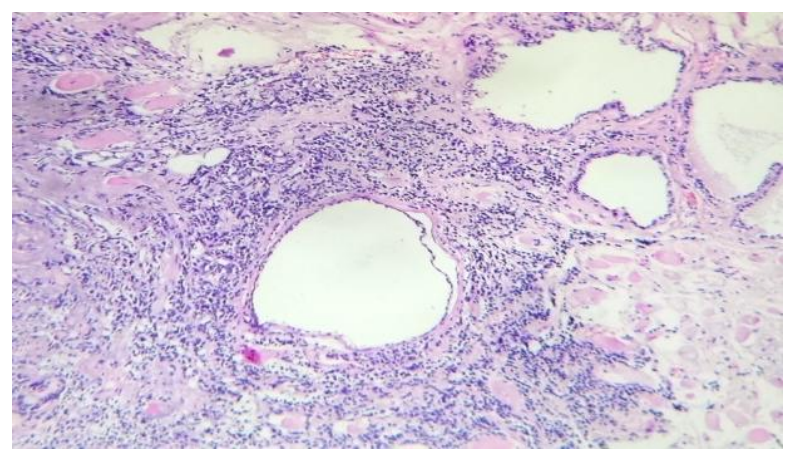

Fig-3A: Prostatic biopsy showing infiltration of lymphoma cells $\mathrm{H}$ and $\mathrm{E}, 10 \mathrm{X}$ 


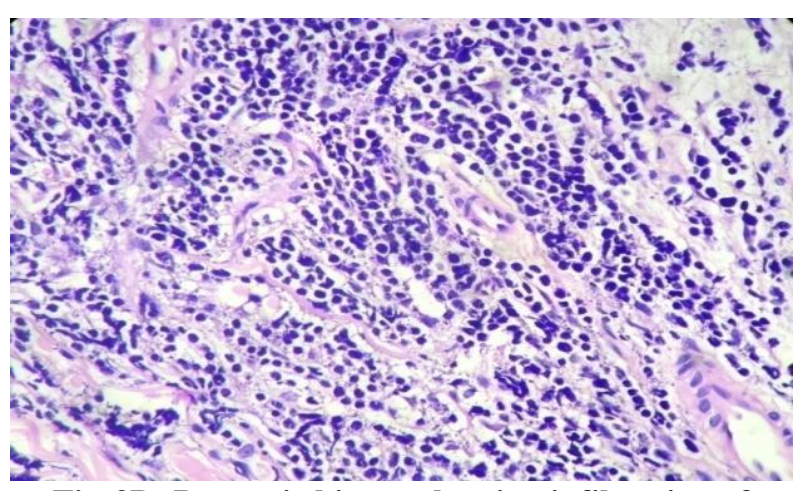

Fig-3B: Prostatic biopsy showing infiltration of lymphoma cells $\mathrm{H}$ and $\mathrm{E}, 10 \mathrm{X}$

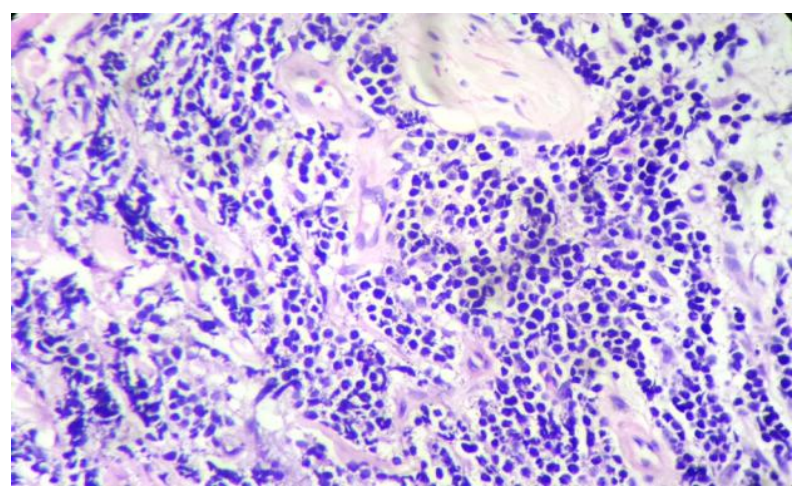

Fig-3C: Prostatic biopsy showing infiltration of lymphoma cells $\mathrm{H}$ and $\mathrm{E}, 20 \mathrm{X}$

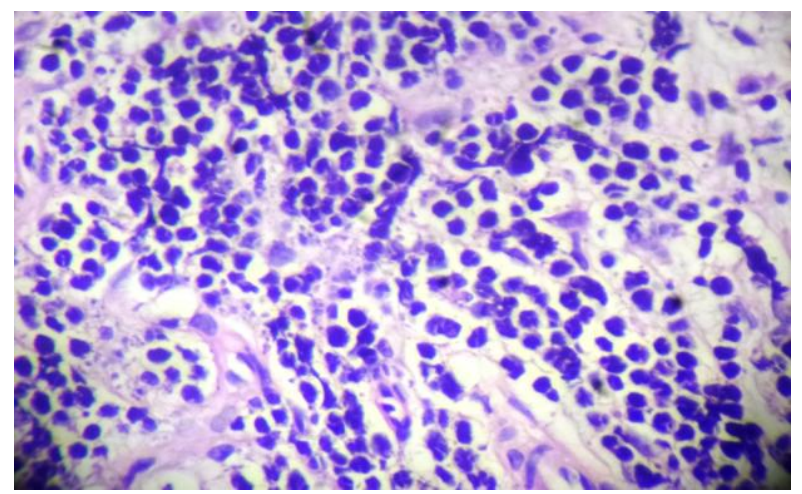

Fig-3D: Prostatic biopsy showing infiltration of lymphoma cells $\mathrm{H}$ and $\mathrm{E}, \mathbf{4 0 X}$

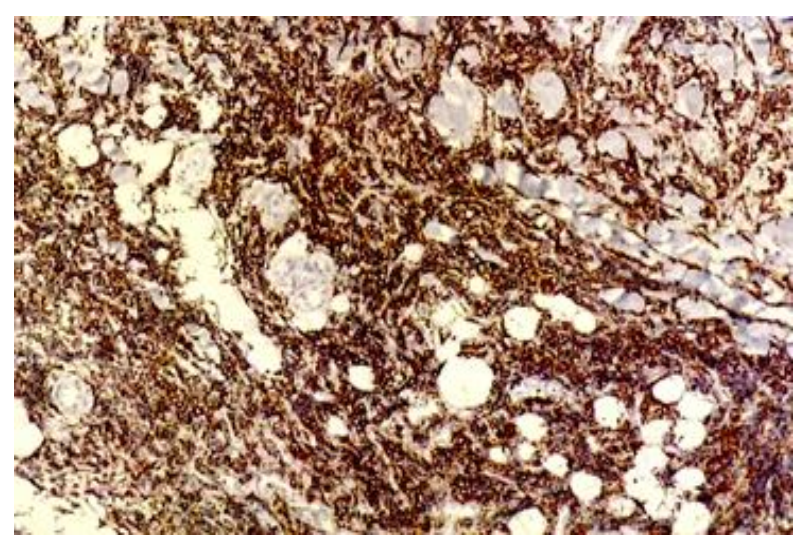

Fig-4A: CD20: Immunoreactive, Score 4+ in dermal lymphoid cells

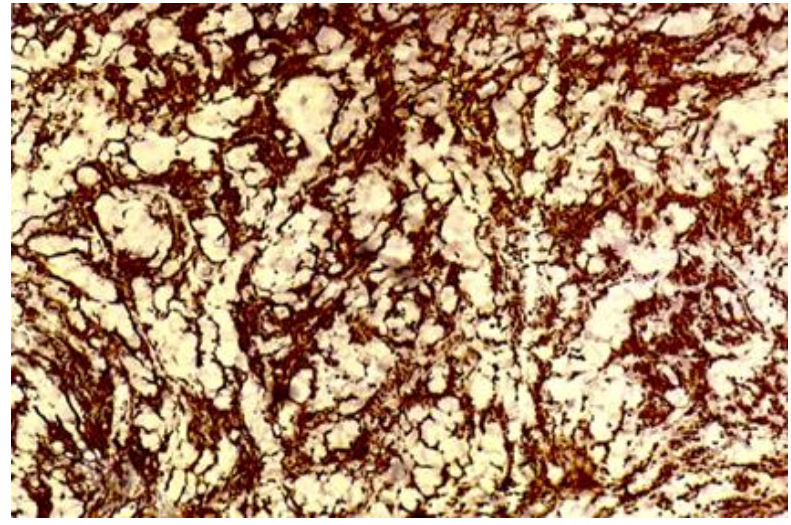

Fig-4B: PAX-5: Immunoreactive, Score 4+ in dermal lymphoid cells

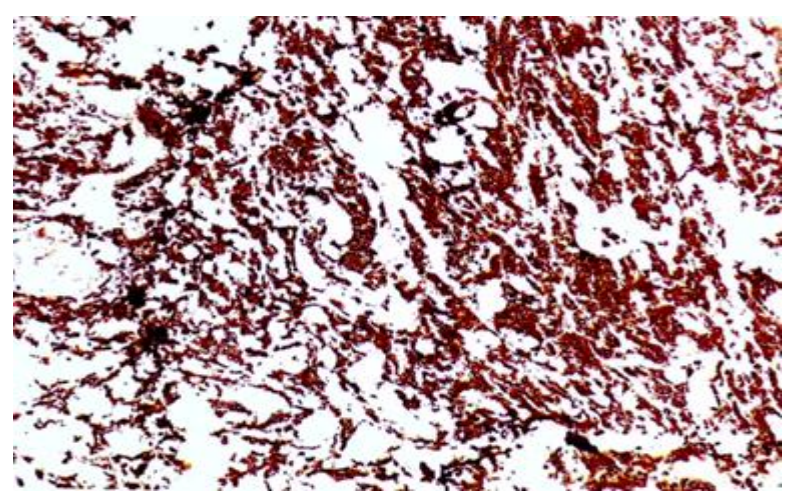

Fig-4C: BCL-2: Immunoreactive, Score 4+ in dermal lymphoid cells

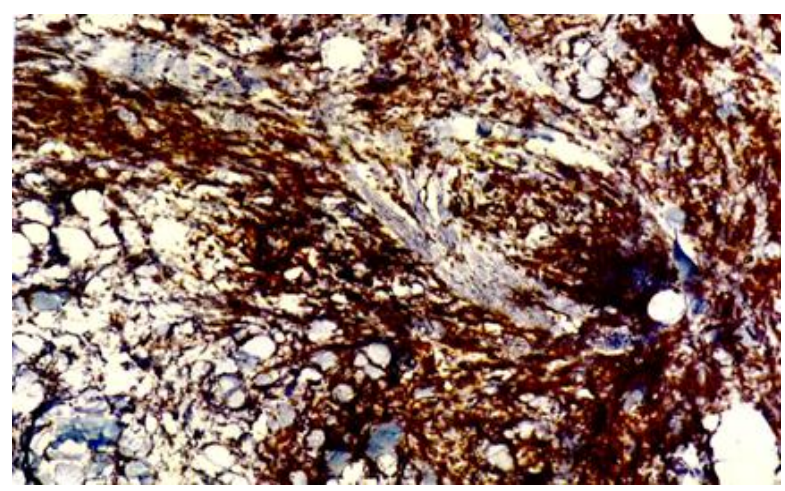

Fig-4D: CD43: Immunoreactive, Score 3+ in dermal lymphoid cells

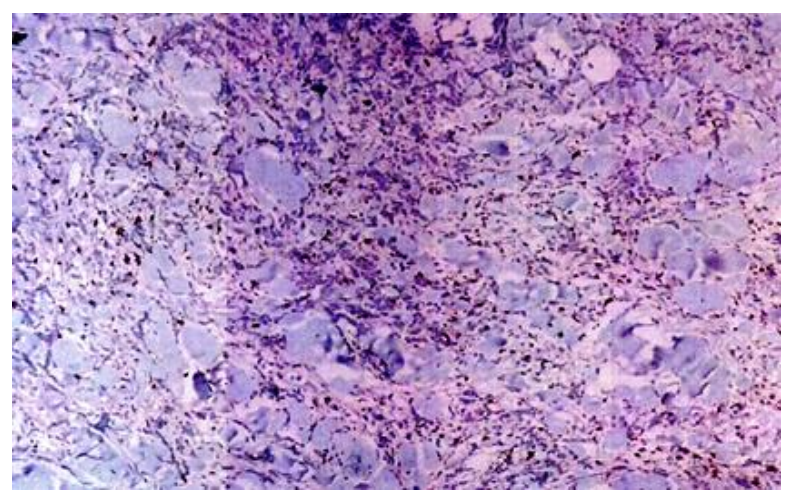

Fig-4E: CD3: Immunoreactive, Score 2+ in focal scattered lymphoid cells 


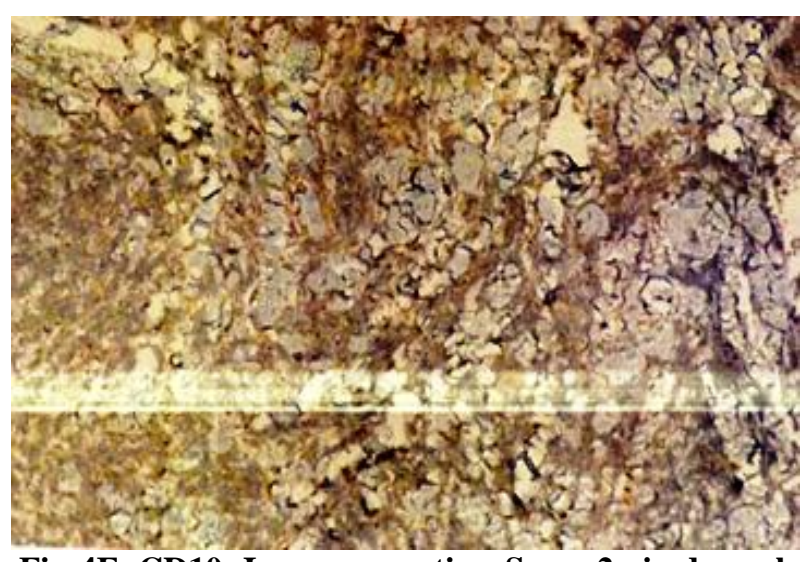

Fig-4F: CD10: Immunoreactive, Score 2+ in dermal lymphoid cells

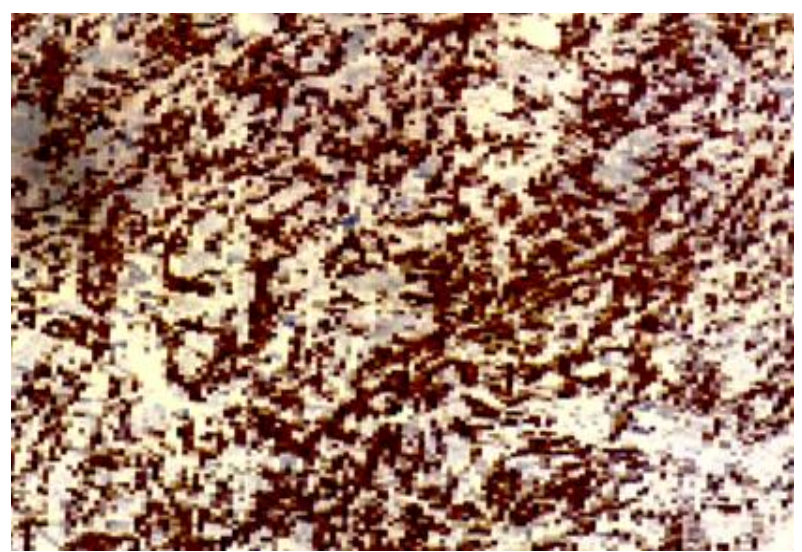

Fig-4G: KI-67: Immunoreactive in approx. $70 \%$ of cells

\section{DISCUSSION}

Cutaneous $\mathrm{T}$ Cell Lymphoma represents approximately $75-80 \%$ of all primary cutaneous lymphomas, whereas primary cutaneous B cell lymphomas account for approximately $20-25 \%$. Moreover, PCDLBL accounts for only 5-10\% of Primary cutaneous B-cell lymphomas [14].

PCDLBCL is common in older women, especially in 70s with male to female ratio of 1:2 to1: 4 [7-11]. The age range is compatible with our case in which our patient is 79 years. PCDLBCL is common in the skin of lower legs. However, other skin covered parts of the body are affected in $10 \%$ to $20 \%$ of the patients [6-11]. In our case patient had multiple lesions in the skin of abdomen and cheek.

Some individuals, particularly those with widespread disease, complain of having the B symptoms of fever, night sweats, and/or weight loss [17]. In our case patient presented with skin lesions and urinary symptoms with loss of appetite and weight loss but no fever or night sweats.

Lymphomas of the prostate are uncommon. Two large consecutive series have shown that less than
$1 \%$ of lymphoma in prostatic specimen [5]. Similarly, in our case there is involvement of the prostate by lymphoma, which makes this a rare case.

Patients with PCDLBCL typically present with rapidly developing red to plum-colored nodules [7, 8]. Although, these lymphomas are limited to the skin at presentation, they often spread to extracutaneous sites mainly lymph nodes, bone marrow and CNS [6, 8, 9, 15]. In our case also patient had extracutaneous involvement in the peripheral blood and genital system (prostate).

Approximately, half of these patients will not survive five years, and those who present with multiple cutaneous tumors often do worse $[6,8,9,11]$. Excisional or punch biopsy is necessary for morphologic and immunohistochemical analysis, and an appropriate staging [6].

Morphologically, PCDLBCL is composed of diffuse, monotonous sheets of large B cells within the dermis with large nuclei that are twice the size of a normal lymphocyte [7]. This round, nuclear morphology identifies the centroblasts and immunoblasts characteristic of this lymphoma and distinguishes these cells from cleaved or irregular nuclear morphology of large centrocytes [6, 7]. Centroblasts have round nuclei with open chromatin and 1 to 3 peripheral nucleoli whereas immunoblasts have single, central nucleolus and often show more abundantly, basophilic cytoplasm [7]. Mitotic figures are relatively sparse $[6,7]$. In our case, the mid-dermis to subcutis showed the presence of diffuse proliferation of small to intermediate sized lymphoid cells, with mild atypia along with crushed lymphoid cells. Typical epidermotropism was not seen.

Peripheral blood smear displayed $18 \%$, atypical cells showing increased nucleo-cytoplasmic ratio with round to oval irregular nuclei, occasionally 1 3 prominent nucleoli, irregularly clumped chromatin and scant amount of agranular cytoplasm.

The prostate biopsy also showed infiltration of intermediate sized atypical lymphoid cells within the prostatic stroma with similar morphology as seen on skin biopsy.

PCDLBCL classically expresses B-cell markers (CD19, CD20, CD22, CD79a, PAX-5) along with additional markers BCL2, IRF4/MUM-1, and FOXP1. However, this immunophenotype is not specific to PCDLBCL and may also be seen in other diffuse large B-cell lymphomas that secondarily involve the skin $[10,11]$. In our case the skin biopsy expressed markers like CD3, CD20, PAX-5, CD10, CD43, and BCL-2. Ki-67 was immunoreactive in $70 \%$ tumor cells which compatible with PCDLBCL. World Health 
Organization Classification of Tumors (Hematopoietic) notes that approximately $10 \%$ of cases of PCDLBCL do not express BCL2 or IRF/MUM1. So, some experts advise not to categorize lymphomas that do not express BCL2 as PCDLBCL instead categorizing them in PCDLBCL-other [10, 13]. Moreover, several studies have shown no correlation between prognosis and expression of BCL2, IRF4/MUM1, or FOXP1 in PCDLBCL [8, 10, 11]. PCDLBCL also commonly expresses BCL6, but typically lacks CD10. Additionally, a recent study identified immunoglobulin $\mathrm{M}(\operatorname{Ig} \mathrm{M})$ as another sensitive marker of PCDLBCL [7, $11]$.

Cytogenetic studies have revealed a frequent inactivation of p15 (INK4b) and p16 (INK4a) as a result of promoter hypermethylation (respectively, $11 \%$ and $44 \%$ of all PCDLBCLs) and chromosomal imbalances in up to $85 \%$ of PCDLBCL (mainly gains of chromosome $2 \mathrm{q}, 3,7 \mathrm{p}, 12 \mathrm{q}, 18 \mathrm{q}$ and losses of $6 \mathrm{q}, 13$, $14,17 \mathrm{p}, 19)$. Translocations of myc, BCL-6, and Ig H genes have been demonstrated by fluorescence in situ hybridization in PCDLBCL but not PCFCL. One gene expression study has revealed an activated B-cell profile in PCDLBCL [16].

\section{CONCLUSION}

It is very rare to detect primary cutaneous diffuse large B-cell lymphoma with involvement of skin, prostate and peripheral blood simultaneously in the same patient.

The prostate is a rare extranodal site of malignant lymphoma. Lymphoma should be considered in the differential diagnosis of lower urinary tract obstruction, particularly in patients with diffuse prostatic enlargement and a prior history of lymphoma. While a variety of primary cutaneous and systemic/ extracutaneous lymphomas may show similar features, the combination of clinical findings, morphology, and immunophenotype helps to distinguish this lymphoma from other diagnostic considerations, with both important prognostic and treatment implications for patients.

\section{REFERENCES}

1. Chen, S., Barnes, J., \& Duncan, L. (2018). Primary cutaneous B-cell lymphomas- clinical and histopathologic features, differential diagnosis, and treatment. Seminars in Cutaneous Medicine and Surgery, 37(1), 49-55.

2. Willemze, R. (2005). WHO-EORTC classification for cutaneous lymphomas. Blood, 105(10), 37683785.

3. Kim, Y., Willemze, R., Pimpinelli, N., Whittaker, S., Olsen, E., \& Ranki, A. (2007). TNM classification system for primary cutaneous lymphomas other than mycosis fungoides and Sézary syndrome: a proposal of the International
Society for Cutaneous Lymphomas (ISCL) and the Cutaneous Lymphoma Task Force of the European Organization of Research and Treatment of Cancer (EORTC). Blood, 110(2), 479-484.

4. Wilcox, R. (2014). Cutaneous B-cell lymphomas: 2015 update on diagnosis, risk-stratification, and management. American Journal of Hematology, 90(1), 73-76.

5. Warrick, J., Owens, S., \& Tomlins, S. (2014). Diffuse Large B-Cell Lymphoma of the Prostate. Archives of Pathology \& Laboratory Medicine, 138(10), 1286-1289.

6. Kim, Y., Willemze, R., Pimpinelli, N., Whittaker, S., Olsen, E., \& Ranki, A. (2007). TNM classification system for primary cutaneous lymphomas other than mycosis fungoides and Sézary syndrome: a proposal of the International Society for Cutaneous Lymphomas (ISCL) and the Cutaneous Lymphoma Task Force of the European Organization of Research and Treatment of Cancer (EORTC). Blood, 110(2), 479-484.

7. Polyatskin, I., Artemyeva, A., \& Krivolapov, Y. (2019). Revised WHO classification of tumors of hematopoietic and lymphoid tissues, 2017 (4th edition): lymphoid tumors. Arkhiv Patologii, 81(3), 59.

8. Grange, F., Beylot-Barry, M., Courville, P., Maubec, E., Bagot, M., \& Vergier, B. (2007). Primary Cutaneous Diffuse Large B-Cell Lymphoma, Leg Type. Archives of Dermatology, 143(9).

9. Zinzani, P., Quaglino, P., Pimpinelli, N., Berti, E. F., Baliva, G., Rupoli, S., \& Bernengo, M. (2006). Prognostic factors in primary cutaneous B-cell lymphoma: the Italian Study Group for Cutaneous Lymphomas. Journal of clinical oncology, 24(9), 1376-1382.

10. Kodama, K., Massone, C., Chott, A., Metze, D., Kerl, H., \& Cerroni, L. (2005). Primary cutaneous large B-cell lymphomas: clinicopathologic features, classification, and prognostic factors in a large series of patients. Blood, 106(7), 2491-2497.

11. Senff, N., Hoefnagel, J., Jansen, P., Vermeer, M., van Baarlen, J., \& Blokx, W. (2007). Reclassification of 300 Primary Cutaneous B-Cell Lymphomas According to the New WHO-EORTC Classification for Cutaneous Lymphomas: Comparison with Previous Classifications and Identification of Prognostic Markers. Journal of Clinical Oncology, 25(12), 1581-1587.

12. Muniesa, C., Pujol, R., Estrach, M., Gallardo, F., García-Muret, M., \& Climent, J. (2012). Primary cutaneous diffuse large B-cell lymphoma, leg type and secondary cutaneous involvement by testicular B-cell lymphoma share identical clinicopathological and immunophenotypical features. Journal of the American Academy of Dermatology, 66(4), 650-654. 
13. Kempf, W., Denisjuk, N., Kerl, K., Cozzio, A., \& Sander, C. (2011). Primary cutaneous B-cell lymphomas. JDDG: Journal Der Deutschen Dermatologischen Gesellschaft, 10(1), 12-23.

14. Willemze, R. (2003). Cutaneous T-Cell Lymphoma: Epidemiology, Etiology, and Classification. Leukemia \& Lymphoma, 44(sup3), S49-S54.

15. Hristov, A. (2012). Primary Cutaneous Diffuse Large B-Cell Lymphoma, Leg Type: Diagnostic Considerations. Archives of Pathology \& Laboratory Medicine, 136(8), 876-881.
16. Selva, R., Violetti, S., Delfino, C., Grandi, V., Cicchelli, S., \& Tomasini, C. (2017). A literature revision in primary cutaneous B-cell lymphoma. Indian Journal of Dermatology, 62(2), 146.

17. Chen, S., Barnes, J., \& Duncan, L. (2018). Primary cutaneous B-cell lymphomas- clinical and histopathologic features, differential diagnosis, and treatment. Seminars in Cutaneous Medicine and Surgery, 37(1), 49-55. 